\title{
Optimized Engagement of Macrophages and Satellite Cells in the Repair and Regeneration of Exercised Muscle
}

\author{
Regula Furrer and Christoph Handschin
}

\begin{abstract}
Recurring contraction-relaxation cycles exert a massive mechanical load on muscle fibers. Training adaptation therefore entails the promotion of a series of biological programs aimed at inducing a better stress response but also at optimizing repair processes. Muscle regeneration is controlled by an intricate, tightly coordinated engagement of muscle fibers, satellite cells, macrophages and other cell types. In this review, we discuss some of the recent insights into the regulation of muscle repair and regeneration in exercised muscle, elucidate the role of the peroxisome proliferator-activated receptor $\gamma$ coactivator $1 \alpha(\mathrm{PGC}-1 \alpha)$ in this context, and speculate about potential implications for the treatment of muscle diseases.
\end{abstract}

\section{Introduction}

Skeletal muscle is a highly plastic organ that adapts its properties depending on contractile demand. These adaptations are not only affected by mechanical loading, e.g., as seen after a period of inactivity or training, but also by the availability of nutrients and hormones, temperature or oxygen levels, which collectively determine the balance between protein synthesis and degradation, mitochondrial activity, contractile function, a shift in fiber type distribution and other biological programs. For example, endurance training promotes mitochondrial function and oxidative metabolism, a shift towards high endurance muscle fibers and tissue vascularization, among other changes. The peroxisome proliferator-activated receptor $\gamma$ coactivator $1 \alpha(\mathrm{PGC}-1 \alpha)$ is an important driver of endurance training adaptation (Lin et al. 2002, 2005; Handschin 2010). Accordingly, PGC-1 $\alpha$ strongly boosts oxidative metabolism, a fiber type shift, glucose uptake, vascularization and other properties of endurance-trained fibers by co-activating a variety of transcription factors in a complex transcriptional network (Handschin 2010; Kupr and Handschin 2015).

R. Furrer $\bullet$ C. Handschin $(\bowtie)$

Biozentrum, University of Basel, Basel, Switzerland

e-mail: christoph.handschin@unibas.ch

B. Spiegelman (ed.), Hormones, Metabolism and the Benefits of Exercise,

Research and Perspectives in Endocrine Interactions,

https://doi.org/10.1007/978-3-319-72790-5_5 
Exercise is one of the best interventions to preserve muscle mass through its strong anti-atrophic effects. As one of the main effectors of exercise adaptation, PGC- $1 \alpha$ also reduces the pathological consequences of muscle wasting. For example, elevation of PGC-1 $\alpha$ in skeletal muscle reduces fiber damage and atrophy and improves muscle functionality in etiologically diverse muscle wasting contexts such as hind limb unloading (Cannavino et al. 2014), denervation or fasting (Sandri et al. 2006), or even Duchenne muscular dystrophy (DMD; Handschin et al. 2007; Selsby et al. 2012; Hollinger et al. 2013). Several mechanisms have been proposed to be involved in the therapeutic effect of PGC-1 $\alpha$ in muscle pathologies, for example, the inhibition of the transcriptional activity of forkhead box O3 (FoxO3) and thereby the induction of E3 ubiquitin ligases muscle ring finger 1 (MuRF-1) and muscle atrophy f-box (MAFbx) that promote protein degradation and fiber atrophy (Sandri et al. 2006). However, other consequences of increased PGC- $1 \alpha$ activity have also been implicated; therefore, the exact mechanisms that underlie the beneficial effect of elevation of PGC- $1 \alpha$ remain unclear. More recently, the involvement of inflammation, both in muscle fibers and through activation of resident macrophages and satellite cells (SCs), the lineage-committed adult muscle stem cells, has been studied in more detail in this context.

\section{Repair and Regeneration After Muscle Damage}

For proper muscle regeneration, a series of highly coordinated events take place that entail a tightly orchestrated cross-talk between different cell types to ensure proper initiation, activation, cell type transition and, ultimately, termination of various cellular programs. Initially, in response to injury, muscle cells and tissue-resident macrophages secrete cytokines and chemokines such as tumor necrosis factor $\alpha$ (TNF $\alpha)$ and $\mathrm{C}-\mathrm{C}$ motif ligand 2/monocyte chemoattractant protein-1 (CCL2/MCP-1) to attract additional immune cells (Pillon et al. 2013). Neutrophils are among the first leukocytes infiltrating the damaged area, and they subsequently release chemotactic signals to promote the tissue infiltration by circulating monocytes (Saclier et al. 2013a). During the initial inflammatory response, monocytes polarize into classical M1-type-activated macrophages and remove tissue debris by phagocytosis. The concomitantly secreted cytokine and chemokine cocktail not only further attracts monocytes but also activates SC proliferation and commitment (Saclier et al. 2013b). The SCs are located in the niche between the sarcolemma and the basal lamina and express different factors depending on the state of the myogenic process. Quiescent SCs are characterized by high levels of paired-box 7 (Pax7). Upon activation, e.g., by muscle injury, proliferation and commitment are initiated by a switch to myogenic regulatory factor 5 (Myf5) and MyoD expression, ultimately resulting in the differentiation into myoblasts and subsequent fusion to myofibers with elevated myogenin and MRF4 (Charge and Rudnicki 2004). This differentiation process is promoted by the shift in macrophage polarization into the alternatively 
activated M2 types that release anti-inflammatory factors (Saclier et al. 2013b). The requirement for a tight orchestration of these different phases is illustrated, for example, by the fibrotic tissue accumulation in the case of a disruption of the regeneration process by a prolongation of the initial pro-inflammatory context, thereby resulting in impaired muscle function. Inversely, a reduced phase involving M1 macrophages may impair regeneration by increased formation of necrotic tissue and inhibition of proliferation of myogenic cells. Therefore, the tight coordination of the transition from M1 to M2 macrophages is critical for proper regeneration.

\section{Effects of Exercise and PGC-1 $\alpha$ on SCs}

In several pathological conditions such as DMD, cancer cachexia and aging, oxidative muscle fibers are preferentially spared, suggesting that these muscle fibers are more protected from muscle damage and degradation. Interestingly, the SC pool in highly oxidative muscle fibers is larger (Gibson and Schultz 1982; Dinulovic et al. 2016b), which could contribute to an improved regeneration after muscle damage. Therefore, inducing a shift towards an oxidative phenotype of the muscle by, for example, exercise (Rowe et al. 2014a), which is also accompanied by a higher SC content (Shefer et al. 2010; Kurosaka et al. 2012; Fry et al. 2014; Abreu et al. 2017), could be a strategy to ameliorate the progression of these pathologies. Even in old muscle, the aging-induced loss of SCs and differentiation potential can be preserved by voluntary wheel running or forced treadmill exercise by increased Wnt signaling (Fujimaki et al. 2014; Cisterna et al. 2016). The rejuvenating effect of exercise on SC function was demonstrated in aged trained mice that recovered to a similar extent as young sedentary animals after muscle injury (Joanisse et al. 2016), indicating that the reduced regenerative capacity of aging muscles could be restored by exercise.

Curiously, even though many of the exercise-induced adaptations in muscle, such as the fiber type shift and oxidative metabolism, are regulated by PGC-1 $\alpha$ (Lin et al. 2002, 2005; Handschin 2010); the number of SCs in mice overexpressing PGC- $1 \alpha$ specifically in muscle $(\mathrm{MCK} \alpha)$ is lower than in wild-type animals and thus diametrically opposite to the higher number seen after exercise or in oxidative muscles (Dinulovic et al. 2016b). Importantly however, despite the reduced SC pool, regeneration is not impaired and the proliferative potential of the SCs is even enhanced in these mice (Dinulovic et al. 2016b). These observations suggest that PGC- $1 \alpha$ indirectly affects SC function by co-activating factors that activate SCs or induce a change in the SC niche (Fig. 1).

The composition of the extracellular matrix (ECM) and the basal lamina determines the efficacy of the niche to modulate SC proliferation and differentiation. For example, fibronectin (FN) is an important niche protein involved in the activation and proliferation of SCs (Bentzinger et al. 2013). Accordingly, the impaired regenerative capacity in aging muscle is associated with reduced levels of FN and can be restored by treating mice with FN (Lukjanenko et al. 2016). It is conceivable, 


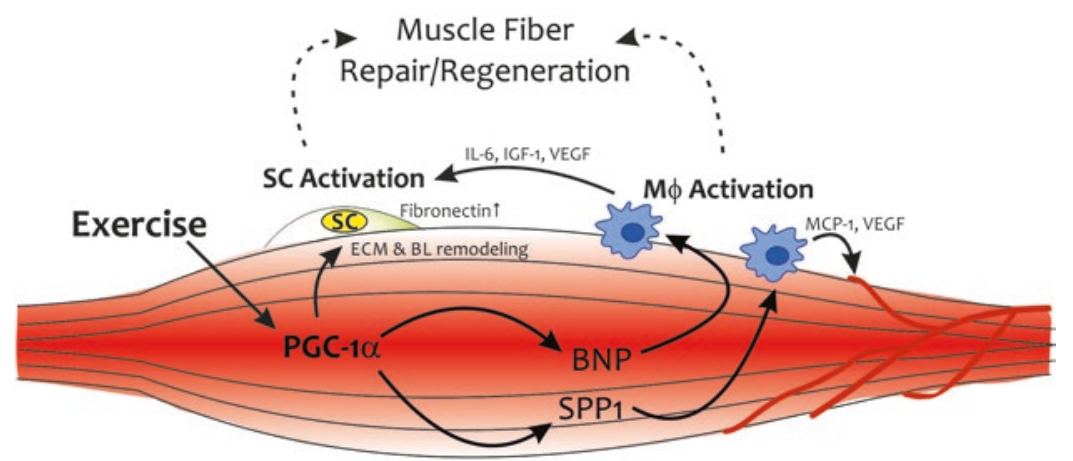

Fig. 1 Pre-conditioning of the muscle for faster regeneration. Schematic representation of the exercise- and PGC- $1 \alpha$-induced muscle cross-talk to macrophages and satellite cells (SC) that creates an environment that could prime the tissue for improved regeneration in response to damage. $E C M$ extracellular matrix, $B L$ basal lamina, $M \phi$ Macrophage

therefore, that the enhanced proliferative potential of SCs of MCK $\alpha$ mice is linked to FN function, since higher levels of FN are observed in the muscles of these animals (Dinulovic et al. 2016b). The increase in matrix metalloproteinases 2 (MMP2) and MMP9 induced by exercise further underscores the importance of niche remodeling, since the ensuing ECM degradation could subsequently facilitate the migration of SCs (Garg and Boppart 2016) whereas MMP-controlled vascularization enhances the delivery of nutrients and growth factors to the niche (Gustafsson 2011). Accordingly, differentiating SCs are closer to capillaries compared to quiescent SCs (Christov et al. 2007). Inversely, SCs are more distantly located from capillaries in old compared to young men (Nederveen et al. 2016), suggesting that the reduced transport of signaling molecules to the niche could contribute to the reduced regenerating potential observed in aging muscles. The angiogenesis induced by exercise or PGC-1 $\alpha$ (Gustafsson 2011; Rowe et al. 2014b) results in a closer proximity of SCs to capillaries; hence there is improved transport of circulating factors to the niche and ultimately enhanced regenerative processes.

\section{Effects of Exercise and PGC-1 $\alpha$ on Macrophages and Inflammation}

In contrast to the numerous studies on the effects of exercise on SCs, literature on exercise-induced changes on macrophages is scarce. Most studies investigating macrophage infiltration in the context of regeneration post-exercise were performed in humans after damaging eccentric exercise (Przybyla et al. 2006; Mahoney et al. 2008; MacNeil et al. 2011), and less is known about the effects of endurance exercise on macrophage infiltration. As infiltration of immune cells is tightly coordinated, the timing of tissue collection is crucial and complicates the experimental 
setup. In response to resistance exercise, infiltration of $\mathrm{CD}^{+} 8^{+}$macrophages is increased after $48 \mathrm{~h}$ (Mahoney et al. 2008; MacNeil et al. 2011) and unchanged in the early ( $3 \mathrm{~h})$ and late (72 h) phases of recovery (Przybyla et al. 2006; Mahoney et al. 2008; MacNeil et al. 2011). The expected switch to CD163 ${ }^{+} \mathrm{M} 2$ macrophages is observed after $72 \mathrm{~h}$, i.e., during the later stage of regeneration (Przybyla et al. 2006). In contrast to the infiltration of macrophages seen $48 \mathrm{~h}$ post-resistance exercise in humans, endurance exercise had no effect on the number of macrophages at that time point in rats (Kurosaka et al. 2012). Therefore, the timing of macrophage activation, infiltration and polarization depends on the type of exercise, training intensity and most likely other factors that remain to be elucidated.

In skeletal muscle fibers, PGC- $1 \alpha$ reduces the expression of pro-inflammatory gene expression by inhibiting the transcriptional activity of the nuclear factor $\mathrm{\kappa B}$ (NF-кB; Eisele et al. 2013). Nevertheless, somewhat unexpectedly, sustained overexpression of PGC- $1 \alpha$ in muscle increases the number of tissue-resident macrophages in uninjured muscle (Rowe et al. 2014b; Dinulovic et al. 2016a). However, these macrophages have a predominant M2 phenotype (Dinulovic et al. 2016a), indicating that PGC- $1 \alpha$ induces an anti-inflammatory environment and may thereby modulate the response to muscle damage. Interestingly, in contrast to the glycolytic phenotype of M1 macrophages, M2 macrophages have a more oxidative phenotype (Galvan-Pena and O'Neill 2014; Kelly and O'Neill 2015), analogous to the metabolic phenotype of muscle overexpressing PGC-1 $\alpha$ or PGC-1 $\beta$. The metabolic shift required for the anti-inflammatory phenotype of macrophages is mediated by PGC-1 $\beta$ (Vats et al. 2006).

Although the mechanisms by which PGC-1 $\alpha$ affects macrophage polarization leading to the higher number of M2 macrophages in muscle is unknown, mediators of PGC-1 $\alpha$-dependent macrophage attraction and/or activation have been described (Fig. 1). PGC-1 $\alpha$ induces the transcription of secreted phosphoprotein 1 (SPP1), which in turn is involved in the recruitment of macrophages and activation of epithelial cells to ensure functional neovascularization (Rowe et al. 2014b). In the context of acute exercise, PGC- $1 \alpha$ controls the expression of the B-type natriuretic peptide (BNP), which promotes macrophage activation in a paracrine manner (Furrer et al. 2017). While M1 macrophage activation is resolved more rapidly in damaged PGC-1 $\alpha$-overexpressing muscles (Dinulovic et al. 2016a), the mechanisms by which muscle PGC- $1 \alpha$ affects infiltration and polarization in this context are still unclear.

\section{Exercise-Induced Pre-conditioning for Faster Muscle Regeneration}

As described above, exercise and muscle PGC- $1 \alpha$ induce several adaptations such as an increase in the SC pool, remodeling of the SC niche, enhancement of the proliferation and differentiation potential of SCs as well as a higher number of 
tissue-resident macrophages that could all contribute to an improved regenerative capacity of the muscle. It is conceivable that exercise creates an environment within the muscle and the niche that could prime the muscle for improved regeneration in response to muscle damage. This hypothesis of exercise-induced pre-conditioning is supported by various observations. For example, the altered tissue-resident macrophage population in muscles overexpressing PGC-1 $\alpha$ could contribute to the improved SC proliferation and commitment in damaged muscles of these mice, since a variety of cytokines and growth factors that activate SCs are secreted by both muscle and macrophages. M1 macrophages release interleukin 6 (IL-6), insulin-like growth factor 1 (IGF-1) and vascular endothelial growth factor (VEGF), whereas M2 macrophages mainly secrete IGF-1 and VEGF (Wu et al. 2010; Lu et al. 2011; Tonkin et al. 2015). IL-6 and IGF-1 are important for the activation and proliferation of SC (Charge and Rudnicki 2004; Serrano et al. 2008) and may thereby contribute not only to the repair and regeneration but, in the case of resistance training, also the hypertrophic response to exercise. Besides the direct effect of IL-6 on SCs, changes in IL-6 levels may also be involved in the remodeling of the niche, as IL-6 KO mice show lower levels of FN (Serrano et al. 2008). These reduced FN levels contribute to impaired regeneration, which is in line with the FN-dependent decrease in regeneration observed in aging (Lukjanenko et al. 2016). Therefore, the number of macrophages as well as the proportion of M1 and M2 macrophages in a trained muscle could play a role in the pre-conditioning of the muscle.

Of note, several of these factors, such as IL-6, IGF-1 and VEGF, are also myokines that are produced and secreted from muscle after exercise (Schnyder and Handschin 2015). Collectively, the local levels of such signaling molecules could, therefore, affect the activation of both macrophages and SCs. For example, elevation of VEGF stimulates angiogenesis and thereby increases vascularization (Gustafsson 2011; Rowe et al. 2014b). The increase in VEGF is directly regulated by PGC-1 $\alpha$ in muscle fibers (Arany et al. 2008; Baresic et al. 2014; Rowe et al. 2014b) and potentially also indirectly through the stimulation of M2 macrophage accumulation (Dinulovic et al. 2016a). The resulting increase in tissue vascularization improves activation of SCs and facilitates infiltration of immune cells.

Besides paracrine effects of muscle and macrophages, exercise-regulated modulation of intrinsic SC properties also influences the proliferation and differentiation potential. For example, isolated SCs of muscles exposed to functional overload fuse better than control SCs (Fujimaki et al. 2016), suggesting that the differentiation potential of SCs is improved by exercise in a manner that is maintained even after removal from the niche. Inactivation of Notch signaling and stimulation of Wnt signaling contribute to improved fusion of trained SCs (Fujimaki et al. 2016), but the exact mechanisms of this priming of SC memory is unclear. Recently, a $\mathrm{G}_{\text {oalert }}$ state of SCs in the contralateral, non-damaged leg of mice with a pharmacologically induced muscle injury has been proposed to be linked to mammalian target of rapamycin complex 1 (mTORC1) activity (Rodgers et al. 2014). This SC pool exhibits an accelerated proliferative response upon activation. Similar to these observations in SCs, muscles may also have a memory in terms of the post-exercise inflammatory response: in human volunteers, MCP-1 levels as well as CD68 ${ }^{+}$ 
macrophages were higher two days after a repeated bout compared to the first bout of exercise (Deyhle et al. 2015). While the mechanisms underlying this finding remain enigmatic, similar exacerbated macrophage activation is observed upon elevation of BNP by PGC- $1 \alpha$ in exercised muscle (Furrer et al. 2017). Moreover, in muscles overexpressing PGC-1 $\alpha$, a larger area of cardiotoxin-damaged muscle is covered by macrophages and thus undergoing regeneration (Dinulovic et al. 2016a). In addition, after chronic muscle damage by multiple cardiotoxin injections, fiber size was recovered more efficiently and fibrotic tissue was reduced by PGC- $1 \alpha$ overexpression (Dinulovic et al. 2016a, b), indicating that exercise- and PGC-1 $\alpha$ induced intrinsic and extrinsic adaptations contributed to enhanced regenerative capacity. Importantly, improved regeneration upon cardiotoxin-induced muscle damage occurred despite strong downregulation of PGC-1 $\alpha$ expression (Dinulovic et al. 2016a, b). These data strongly imply a pre-conditioning effect to help trained muscle to cope with damage that includes a broad spectrum of functional modulation of SCs, endothelial cells and macrophages as well as cellular cross-talk that together create an environment that primes the muscle for faster regeneration.

\section{Conclusion}

Overexpression of PGC-1 $\alpha$ in skeletal muscle ameliorates the symptoms of many different muscle diseases. Similarly, in those pathologies in which patients are exercise tolerant, training confers a beneficial effect on muscle functionality. While many different properties of exercise and PGC-1 $\alpha$ most likely contribute to this therapeutic effect, the modulation and orchestration of macrophages and SCs could directly improve repair and regeneration in these diseases. Therefore, a more careful elucidation of the cell autonomous changes and cellular cross-talk that optimize repair and regeneration of damaged muscle tissue after exercise could provide novel targets and avenues to treat a wide variety of different muscle diseases.

Acknowledgments The work in our group related to the topic of this review is supported by the Swiss National Science Foundation, the European Research Council (ERC) Consolidator grant 616830-MUSCLE_NET, Swiss Cancer Research grant KFS-3733-08-2015, the Swiss Society for Research on Muscle Diseases (SSEM), SystemsX.ch and the University of Basel.

\section{References}

Abreu P, Mendes SV, Ceccatto VM, Hirabara SM (2017) Satellite cell activation induced by aerobic muscle adaptation in response to endurance exercise in humans and rodents. Life Sci 170:33-40

Arany Z, Foo SY, Ma Y, Ruas JL, Bommi-Reddy A, Girnun G, Cooper M, Laznik D, Chinsomboon J, Rangwala SM, Baek KH, Rosenzweig A, Spiegelman BM (2008) HIF-independent 
regulation of VEGF and angiogenesis by the transcriptional coactivator PGC-1alpha. Nature 451:1008-1012

Baresic M, Salatino S, Kupr B, van Nimwegen E, Handschin C (2014) Transcriptional network analysis in muscle reveals AP-1 as a partner of PGC-1alpha in the regulation of the hypoxic gene program. Mol Cell Biol 34:2996-3012

Bentzinger CF, Wang YX, von Maltzahn J, Soleimani VD, Yin H, Rudnicki MA (2013) Fibronectin regulates Wnt7a signaling and satellite cell expansion. Cell Stem Cell 12:75-87

Cannavino J, Brocca L, Sandri M, Bottinelli R, Pellegrino MA (2014) PGC1-alpha over-expression prevents metabolic alterations and soleus muscle atrophy in hindlimb unloaded mice. J Physiol 592:4575-4589

Charge SB, Rudnicki MA (2004) Cellular and molecular regulation of muscle regeneration. Physiol Rev 84:209-238

Christov C, Chretien F, Abou-Khalil R, Bassez G, Vallet G, Authier FJ, Bassaglia Y, Shinin V, Tajbakhsh S, Chazaud B, Gherardi RK (2007) Muscle satellite cells and endothelial cells: close neighbors and privileged partners. Mol Biol Cell 18:1397-1409

Cisterna B, Giagnacovo M, Costanzo M, Fattoretti P, Zancanaro C, Pellicciari C, Malatesta M (2016) Adapted physical exercise enhances activation and differentiation potential of satellite cells in the skeletal muscle of old mice. J Anat 228:771-783

Deyhle MR, Gier AM, Evans KC, Eggett DL, Nelson WB, Parcell AC, Hyldahl RD (2015) Skeletal muscle inflammation following repeated bouts of lengthening contractions in humans. Front Physiol 6:424

Dinulovic I, Furrer R, Di Fulvio S, Ferry A, Beer M, Handschin C (2016a) PGC-1alpha modulates necrosis, inflammatory response, and fibrotic tissue formation in injured skeletal muscle. Skelet Muscle 6:38

Dinulovic I, Furrer R, Beer M, Ferry A, Cardel B, Handschin C (2016b) Muscle PGC-1 $\alpha$ modulates satellite cell number and proliferation by remodeling the stem cell niche. Skelet Muscle 6:39

Eisele PS, Salatino S, Sobek J, Hottiger MO, Handschin C (2013) The peroxisome proliferatoractivated receptor gamma coactivator 1alpha/beta (PGC-1) coactivators repress the transcriptional activity of NF-kappaB in skeletal muscle cells. J Biol Chem 288:2246-2260

Fry CS, Noehren B, Mula J, Ubele MF, Westgate PM, Kern PA, Peterson CA (2014) Fibre typespecific satellite cell response to aerobic training in sedentary adults. J Physiol 592:2625-2635

Fujimaki S, Hidaka R, Asashima M, Takemasa T, Kuwabara T (2014) Wnt protein-mediated satellite cell conversion in adult and aged mice following voluntary wheel running. J Biol Chem 289:7399-7412

Fujimaki S, Machida M, Wakabayashi T, Asashima M, Takemasa T, Kuwabara T (2016) Functional overload enhances satellite cell properties in skeletal muscle. Stem Cells Int 2016:7619418

Furrer R, Eisele PS, Schmidt A, Beer M, Handschin C (2017) Paracrine cross-talk between skeletal muscle and macrophages in exercise by PGC-1 $\alpha$-controlled BNP. Sci Rep 7:40789

Galvan-Pena S, O'Neill LA (2014) Metabolic reprograming in macrophage polarization. Front Immunol 5:420

Garg K, Boppart MD (2016) Influence of exercise and aging on extracellular matrix composition in the skeletal muscle stem cell niche. J Appl Physiol (1985) 121:1053-1058

Gibson MC, Schultz E (1982) The distribution of satellite cells and their relationship to specific fiber types in soleus and extensor digitorum longus muscles. Anat Rec 202:329-337

Gustafsson T (2011) Vascular remodelling in human skeletal muscle. Biochem Soc Trans 39:1628-1632

Handschin C (2010) Regulation of skeletal muscle cell plasticity by the peroxisome proliferatoractivated receptor gamma coactivator 1alpha. J Recept Signal Transduct Res 30:376-384

Handschin C, Kobayashi YM, Chin S, Seale P, Campbell KP, Spiegelman BM (2007) PGC-1alpha regulates the neuromuscular junction program and ameliorates Duchenne muscular dystrophy. Genes Dev 21:770-783 
Hollinger K, Gardan-Salmon D, Santana C, Rice D, Snella E, Selsby JT (2013) Rescue of dystrophic skeletal muscle by PGC-1alpha involves restored expression of dystrophin-associated protein complex components and satellite cell signaling. Am J Physiol Regul Integr Comp Physiol 305:R13-R23

Joanisse S, Nederveen JP, Baker JM, Snijders T, Iacono C, Parise G (2016) Exercise conditioning in old mice improves skeletal muscle regeneration. FASEB J 30:3256-3268

Kelly B, O'Neill LA (2015) Metabolic reprogramming in macrophages and dendritic cells in innate immunity. Cell Res 25:771-784

Kupr B, Handschin C (2015) Complex coordination of cell plasticity by a PGC-1alpha-controlled transcriptional network in skeletal muscle. Front Physiol 6:325

Kurosaka M, Naito H, Ogura Y, Machida S, Katamoto S (2012) Satellite cell pool enhancement in rat plantaris muscle by endurance training depends on intensity rather than duration. Acta Physiol (Oxf) 205:159-166

Lin J, Wu H, Tarr PT, Zhang CY, Wu Z, Boss O, Michael LF, Puigserver P, Isotani E, Olson EN, Lowell BB, Bassel-Duby R, Spiegelman BM (2002) Transcriptional co-activator PGC-1 alpha drives the formation of slow-twitch muscle fibres. Nature 418:797-801

Lin J, Handschin C, Spiegelman BM (2005) Metabolic control through the PGC-1 family of transcription coactivators. Cell Metab 1:361-370

Lu H, Huang D, Saederup N, Charo IF, Ransohoff RM, Zhou L (2011) Macrophages recruited via CCR2 produce insulin-like growth factor-1 to repair acute skeletal muscle injury. FASEB J 25:358-369

Lukjanenko L et al (2016) Loss of fibronectin from the aged stem cell niche affects the regenerative capacity of skeletal muscle in mice. Nat Med 22:897-905

MacNeil LG, Baker SK, Stevic I, Tarnopolsky MA (2011) 17beta-estradiol attenuates exercise-induced neutrophil infiltration in men. Am J Physiol Regul Integr Comp Physiol 300:R1443-R1451

Mahoney DJ, Safdar A, Parise G, Melov S, Fu M, MacNeil L, Kaczor J, Payne ET, Tarnopolsky MA (2008) Gene expression profiling in human skeletal muscle during recovery from eccentric exercise. Am J Physiol Regul Integr Comp Physiol 294:R1901-R1910

Nederveen JP, Joanisse S, Snijders T, Ivankovic V, Baker SK, Phillips SM, Parise G (2016) Skeletal muscle satellite cells are located at a closer proximity to capillaries in healthy young compared with older men. J Cachexia Sarcopenia Muscle 7:547-554

Pillon NJ, Bilan PJ, Fink LN, Klip A (2013) Cross-talk between skeletal muscle and immune cells: muscle-derived mediators and metabolic implications. Am J Physiol Endocrinol Metab 304:E453-E465

Przybyla B, Gurley C, Harvey JF, Bearden E, Kortebein P, Evans WJ, Sullivan DH, Peterson CA, Dennis RA (2006) Aging alters macrophage properties in human skeletal muscle both at rest and in response to acute resistance exercise. Exp Gerontol 41:320-327

Rodgers JT, King KY, Brett JO, Cromie MJ, Charville GW, Maguire KK, Brunson C, Mastey N, Liu L, Tsai CR, Goodell MA, Rando TA (2014) mTORC1 controls the adaptive transition of quiescent stem cells from $\mathrm{G}(0)$ to G(Alert). Nature 510:393-396

Rowe GC, Safdar A, Arany Z (2014a) Running forward: new frontiers in endurance exercise biology. Circulation 129:798-810

Rowe GC, Raghuram S, Jang C, Nagy JA, Patten IS, Goyal A, Chan MC, Liu LX, Jiang A, Spokes KC, Beeler D, Dvorak H, Aird WC, Arany Z (2014b) PGC-1alpha induces SPP1 to activate macrophages and orchestrate functional angiogenesis in skeletal muscle. Circ Res 115:504-517

Saclier M, Cuvellier S, Magnan M, Mounier R, Chazaud B (2013a) Monocyte/macrophage interactions with myogenic precursor cells during skeletal muscle regeneration. FEBS J 280:4118-4130

Saclier M, Yacoub-Youssef H, Mackey AL, Arnold L, Ardjoune H, Magnan M, Sailhan F, Chelly J, Pavlath GK, Mounier R, Kjaer M, Chazaud B (2013b) Differentially activated macrophages orchestrate myogenic precursor cell fate during human skeletal muscle regeneration. Stem Cells 31:384-396 
Sandri M, Lin J, Handschin C, Yang W, Arany ZP, Lecker SH, Goldberg AL, Spiegelman BM (2006) PGC-1alpha protects skeletal muscle from atrophy by suppressing FoxO3 action and atrophy-specific gene transcription. Proc Natl Acad Sci USA 103:16260-16265

Schnyder S, Handschin C (2015) Skeletal muscle as an endocrine organ: PGC-1alpha, myokines and exercise. Bone 80:115-125

Selsby JT, Morine KJ, Pendrak K, Barton ER, Sweeney HL (2012) Rescue of dystrophic skeletal muscle by PGC-1alpha involves a fast to slow fiber type shift in the mdx mouse. PLoS One 7:e30063

Serrano AL, Baeza-Raja B, Perdiguero E, Jardi M, Munoz-Canoves P (2008) Interleukin-6 is an essential regulator of satellite cell-mediated skeletal muscle hypertrophy. Cell Metab 7:33-44

Shefer G, Rauner G, Yablonka-Reuveni Z, Benayahu D (2010) Reduced satellite cell numbers and myogenic capacity in aging can be alleviated by endurance exercise. PLoS One 5:e13307

Tonkin J, Temmerman L, Sampson RD, Gallego-Colon E, Barberi L, Bilbao D, Schneider MD, Musaro A, Rosenthal N (2015) Monocyte/macrophage-derived IGF-1 orchestrates murine skeletal muscle regeneration and modulates autocrine polarization. Mol Ther 23:1189-1200

Vats D, Mukundan L, Odegaard JI, Zhang L, Smith KL, Morel CR, Wagner RA, Greaves DR, Murray PJ, Chawla A (2006) Oxidative metabolism and PGC-1beta attenuate macrophagemediated inflammation. Cell Metab 4:13-24

Wu WK, Llewellyn OP, Bates DO, Nicholson LB, Dick AD (2010) IL-10 regulation of macrophage VEGF production is dependent on macrophage polarisation and hypoxia. Immunobiology 215:796-803

Open Access This chapter is licensed under the terms of the Creative Commons Attribution 4.0 International License (http://creativecommons.org/licenses/by/4.0/), which permits use, sharing, adaptation, distribution and reproduction in any medium or format, as long as you give appropriate credit to the original author(s) and the source, provide a link to the Creative Commons license and indicate if changes were made.

The images or other third party material in this chapter are included in the chapter's Creative Commons license, unless indicated otherwise in a credit line to the material. If material is not included in the chapter's Creative Commons license and your intended use is not permitted by statutory regulation or exceeds the permitted use, you will need to obtain permission directly from the copyright holder.

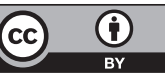

